\title{
A Comprehensive Roadmap Towards Generation of Influenza B Reporter Assay Using a Single DNA Polymerase Based Cloning of Reporter RNA Construct.
}

Nandita Kedia ${ }^{1}$, Saptarshi Banerjee ${ }^{1}$, Arindam Mondal ${ }^{1 *}$

${ }^{1}$ School of Bioscience, Indian Institute of Technology Kharagpur, Kharagpur -721302, India

${ }^{*}$ Corresponding author

\section{Abstract:}

Mini-genome reporter assay is a key tool for conducting RNA virus research. But, procedural complications and lack of adequate literature pose major challenge towards developing these assay systems. Here we present a novel yet generic and simple cloning strategy for construction of influenza B virus reporter RNA template and describe extensive standardization of the reporter RNP/ polymerase activity assay for monitoring viral RNA synthesis in infection free setting. Using this assay system, we, for the first time showed the effect of viral protein NS1 and host protein PKC-Delta upon influenza B virus RNA synthesis. Additionally, the assay system showed promising results in evaluating efficacy of antiviral drugs targeting viral RNA synthesis and virus propagation. Together, this work offers a detailed protocol for standardization of influenza virus mini-genome assay and an excellent tool for screening of host factors and antivirals in a fast, user friendly and high throughput manner.

\section{Keywords:}

21 Influenza B virus, engineering reporter construct, ribonucleoprotein particles, reporter based activity assay, screening of host factors and antivirals.

\section{Introduction:}

First discovered in 1940[1], the influenza B virus has since been causing significant morbidity and mortality in the global population[2]. As per the recent surveillance (seasons 2010-2018) influenza B viruses are responsible for $15-30 \%$ of the total influenza like illness, with a number of complications like fevers, body ache, fatigue and even life threatening acute respiratory distress syndrome for patients having pre-existing lung diseases[3,4]. There are two different lineages of influenza B virus, Victoria and Yamagata, which circulate in the human population with various degrees of predominance in different influenza seasons $[5,6]$. Due to constant increase in the influenza $B$ virus related infections and limited cross protection offered by influenza B vaccine against both of these lineages, there is a gradual transition from trivalent (against two subtypes of FluA and one lineage of FluB) to quadrivalent (against two subtypes of FluA and two lineages of FluB) flu shots offered across the world[7]. In spite of its immense importance in the context of global healthcare ecosystem, influenza $B$ virus research has drawn significantly lesser attention in comparison to the closely related influenza A viruses, largely due to the scarcity of the tools required to study virus replication cycle. This also severely restricts antiviral drug discovery directed towards influenza B virus therapy[8].

Influenza viruses are segmented negative sense RNA viruses of the Orthomyxoviridae family. Amongst the four types A, B, C and D, only influenza A and B cause human epidemics[9]. Viral 
genome consists of eight different segments each of which remains enwrapped with multiple copies of nucleoprotein (NP) in their oligomeric form and associates with a single copy of RNA dependent RNA polymerase (RdRp) to form the ribonucleoprotein complexs or RNPs[10]. RNPs are the self-sufficient machinery for driving different modes of RNA dependent RNA synthesis events including viral gene expression and genome replication, hence reside at the center of virus replication cycle[11]. This is why reporter RNP based assay systems remain one of the invaluable tools for studying virus replication, host-pathogen interaction and high-throughput screening of antivirals without handling infectious virus particles and hence avoiding biosafety associated procedural complications[12, 13].

Influenza virus genomic segments are single stranded RNA that are devoid of the 5'-Cap and 3'Poly(A) tail structures[14]. Different segments harbor conserved untranslated regions of variable lengths both at the 5' and 3' ends, which bracket single or multiple open reading frames (in the antisense orientation) encoding viral proteins[14, 15]. Terminal regions of the 5' and 3' UTRs contain complementarity resulting in a partial duplex structure (also known as "panhandle RNA" or "cork-screw RNA") that serves as the promoter for RdRp[16]. Additionally, the UTRs contain cis-acting elements, necessary and sufficient for transcription and replication of viral[17-19]and non-viral reporter genes[12, 16, 20, 21]. Several groups have established reporter RNA based assay systems where viral open reading frames have been replaced with reporter genes of fluorescence or chemiluminescent proteins[12, 13, 16, 22-25]. These reporter RNA templates, when expressed inside the cells in combination with NP and RdRp proteins, reconstitute reporter RNPs. RNA synthesis activity of these RNPs could be measured by quantifying the extent of reporter gene expression. Although appears to be straightforward, successful establishment of reporter assay system requires (i) complicated cloning strategies to synthesize the reporter RNA construct, (ii) construction of plasmids for expression of viral NP and RdRp subunits (PB1, PB2 and PA), and (iii) optimized expression of the reporter RNA and viral proteins in required stoichiometric amounts that leads to the reconstruction of reporter RNPs with maximum efficiency.

So far, different strategies have been used to construct plasmids expressing influenza $A$ and $B$ virus reporter RNA template (reporter plasmids)[12, 13, 24-26]. In few studies, reporter luciferase gene was amplified using primers containing long overhangs corresponding to 3' and 5' UTR regions of influenza $A$ or $B$ viruses; resulting PCR fragment harboring luciferase ORF flanked by the viral UTRs were then inserted into the target vector for RNA polymerase-I driven expression of the same, using conventional restriction digestion and subsequent ligation method[12, 21, 27]. Alternatively, viral 5' and 3'-UTR containing vectors (amplified using inverse PCR from the cDNA clone of the corresponding segment) were ligated with reporter gene insert predigested with compatible restriction enzyme sites[28]. In an independent cloning strategy, a double-stranded DNA linker encompassing 5' and 3'-UTRs was inserted into the vector in-between the Pol-I promoter and terminator sequences with the help of compatible restriction enzyme sites. The reporter gene was then inserted between the UTRs using a second restriction enzyme site[24]. These restriction enzyme based cloning strategies are laborious and often introduce additional nucleotides between the UTRs and the reporter gene which may interfere with the activity of the cis/trans acting elements[24]. In order to avoid these constraints, restriction enzyme free cloning 
implemented. For example, inserts containing reporter genes flanked by the 5' and 3'-UTRs were created using long overhang primers (containing the UTR regions) which was then stitched to the vector through the use of specialized proprietary enzymes/kits[13, 29]. With the inherent limitations of the aforesaid cloning techniques, scarcity of information about the extensive experimental protocol makes it difficult to establish and standardize the reporter based RNP activity assay for influenza viruses. This situation gets further complicated for influenza $B$ viruses due to the larger size of the UTRs compared to the same for influenza A viruses.

Here we present a novel yet fairly simple cloning strategy, independent of any restriction enzyme or specialized reagents or kits, to construct a firefly luciferase based reporter plasmid capable of generating reporter genome template for influenza B/Brisbane/60/2008 virus. Additionally, we present extensive standardization of this reporter plasmid based RNP activity assay through optimization of various parameters regulating viral RNA synthesis. Using the reporter assay system, we showed for the first time the effect of viral non-structural protein-1 (NS1) and host protein kinase $C$ delta (PKCD) upon influenza $B$ virus RNA synthesis. We also demonstrated the ability of this assay system to be used as a high throughput screening platform for the identification of antiviral drugs specifically inhibiting RNA polymerase activity of the virus. Together this work presents a great resource for cloning, standardization and implementation of reporter based RNP activity assay for influenza and other related viruses.

\section{Materials and methods:}

\section{Cell lines and Viruses} Human embryonic kidney 293T (HEK 293T) cells were maintained in Dulbecco's modified Eagle's medium (DMEM; Invitrogen, Cat no. \#12800017) supplemented with $10 \%(\mathrm{v} / \mathrm{v})$ fetal bovine serum (FBS; Invitrogen, Cat no. \#10082147), 2mM GlutaMAX ${ }^{\mathrm{TM}}$ (Invitrogen, Cat no. \#35050061), 1\% penicillin-streptomycin (Invitrogen, Cat no. \#1514122) incubated at $37^{\circ} \mathrm{C}$ in a humidified $5 \% \mathrm{CO}_{2}$ incubator. Madin-Darby Canine Kidney (MDCK) cells were maintained in same conditions with 10\% FBS (FBS; Invitrogen Cat no. \#10270106). Influenza B/Brisbane/60/2008 virus was used in this study.

\section{Virus amplification and RNA Extraction}

$3 \times 10^{6} \mathrm{MDCK}$ cells were seeded in $10 \mathrm{~cm}$ dishes, 24 hours before the infection. Prior to infection, cell monolayer was washed with PBS twice and subsequently infected at an M.O.I. of 0.001. For each $10 \mathrm{~cm}$ plate, $1 \mathrm{~mL}$ virus inoculum was prepared in virus growth media (VGM; containing DMEM, 0.2\% bovine serum albumin (Sigma; Cat no. \#A8412), $25 \mathrm{mM} \mathrm{N}$-(2-hydroxyethyl) piperazine-N'-ethanesulfonic acid (HEPES; Invitrogen, Cat no. \#15630080) buffer, 2mM GlutaMAX ${ }^{\mathrm{TM}}$, $1 \%$ penicillin-streptomycin and $0.5 \mu \mathrm{g} / \mathrm{mL}$ TPCK-trypsin (Thermo Scientific ${ }^{\mathrm{TM}}$, Cat no. \#20233)). Virus attachment was performed with $1 \mathrm{ml}$ of inoculum for 1 hour at $37^{\circ} \mathrm{C}$ in humidified $5 \% \mathrm{CO}_{2}$ incubator with intermittent shaking at every 10 minutes to prevent drying of cell monolayer and homogenous distribution of the inoculum. Post attachment, each $10 \mathrm{~cm}$ plate was supplemented with $6 \mathrm{~mL}$ of VGM and incubated either at $37^{\circ} \mathrm{C}$ for Influenza $A$ virus and $33^{\circ} \mathrm{C}$ for Influenza B virus in humidified $5 \% \mathrm{CO}_{2}$ incubator. At 72 hours post infection, supernatant was collected and centrifuged at $3200 \mathrm{~g}$ for 10 minutes at $4^{\circ} \mathrm{C}$ to remove the cell debris. The 
supernatants were collected and aliquots were stored at $80^{\circ} \mathrm{C}$ refrigerator for further applications[30].

\section{Reverse transcription (RT)-PCR}

Viral RNA was extracted from amplified virus stock using Trizol reagent (Invitrogen; Cat no. \#15596018). Reverse transcription was carried out using primer 'Uni9', which is complementary to all of the individual genomic RNA segments of Influenza B/Brisbane/60/2008 virus[31] with Verso cDNA Synthesis Kit (Thermo Scientific ${ }^{\mathrm{TM}}$; \#AB1453A) according to manufacturer's instructions. After the RT reaction, segment 6 (NA-NB) of the viral genome was amplified using the 'NA-NB_F' and 'NA-NB_R' primers with the help of Phusion High-Fidelity DNA Polymerase (Thermo Scientific ${ }^{\mathrm{TM}}$, Cat no. \#F530S). The PCR product was purified using PCR Purification Kit (Invitrogen; Cat No. \# K310001) and the yield and quality of the purified product was checked measuring the absorbance at 260 and $280 \mathrm{~nm}$ and subsequently by running it on agarose gel.

\section{PCR and Cloning}

i) Amplification of 5' and 3' UTR: The RT-PCR amplified DNA corresponding to segment 6 of viral genome was used as a template for the amplification of 5'UTR and 3'UTR using Phusion High-Fidelity DNA Polymerase using 5' UTR_F, 5' UTR_R and 3' UTR_F, 3' UTR_R primers pairs and the PCR product were purified using Quick gel extraction kit (Invitrogen: Cat no. \# K210012). The purified double-stranded 5'UTR fragment and 3'UTR fragment were then used as primers for the amplification of luciferase gene described in the next section.

ii) Preparation of Insert: The luciferase ORF was amplified using the pHH21-vNA-Luc as a template, kindly provided by Dr. Andrew Mehle. The double-stranded 5'UTR and 3'UTR fragments, synthesized in the previous step, were used as primers (5uM final concentration) for the PCR amplification of Luciferase ORF using Phusion high fidelity DNA polymerase, following manufacturer's protocol. The PCR product was analyzed on $0.8 \%$ agarose gel and purified using PCR purification kit.

iii) Preparation of Vector: The vector was amplified using the pHH21-vNA-Luc as a template. PHH21_F' \& 'PHH21_R' primers were used to amplify and linearize the vector using Phusion high fidelity DNA polymerase using 5x Phusion GC rich buffer following manufacturers' protocol. The PCR product was analyzed on $0.8 \%$ agarose gel and purified using PCR purification kit.

iv) Circular Polymerase Extension Cloning: In the final CPEC assembly reaction, the purified linearized vector and inserts are mixed together maintaining a vector to insert molar ratio $(\mathrm{V}: \mathrm{I})=1: 1,1: 2$ or $1: 3$, with the PCR reaction components, that consists of 0.4 ul of $40 \mathrm{mM}$ dNTPs, $4 \mathrm{ul}$ of $5 x$ Phusion HF Buffer, $0.25 \mu \mathrm{l}$ of Phusion High-Fidelity DNA Polymerase, 100ng of Vector and required amount of Insert to make the final volume of 20ul. The composition of the CPEC reaction is identical to that of a standard Phusion PCR mix, except that, there is a high concentration of dNTPs and no primers are added. The thermal cycling conditions were as follows: $98 \circ \mathrm{C}$ for $30 \mathrm{~s}, 25$ cycles of $98{ }^{\circ} \mathrm{C}$ for $10 \mathrm{~s}, 72{ }^{\circ} \mathrm{C}$ for $1 \mathrm{~min} 30 \mathrm{~s}$, followed by $72{ }^{\circ} \mathrm{C}$ for $10 \mathrm{~min}$. To assess if a CPEC reaction is successful or not, $5 \mathrm{ul}$ of the product was analyzed by agarose gel 
electrophoresis. The $\mathrm{V}: \mathrm{I}=1: 3$ reaction showing highest intensity of the high molecular weight band corresponding to the total length of vector and Insert was selected for transformation.

\section{Transformation}

E. Coli. DH5 alpha competent cells were prepared by modified rubidium chloride method as described by Glover et al[32]. For transformation, 10ul of the CPEC reaction mixture were added to the competent cells. Followed by an incubation of 30 minutes, cells were subjected to a brief heat shock at $42^{\circ} \mathrm{C}$ for 35 seconds followed by 5 minutes incubation in ice. Cells were then grown in 400 ul of Luria bertani broth (Himedia, Cat no. \# M1245; $2.5 \%$ in double distilled water) at $37^{\circ} \mathrm{C}$ incubator for 1.5 hours with shaking at 220rpm and the entire culture volume was spread upon LB-agar plates containing $100 \mathrm{ug} / \mathrm{ml}$ of Ampicillin. Colony PCR was performed to identify positive clones which were then verified through Sanger sequencing.

\section{Generation of polymerase protein expressing plasmids}

The PB2, PB1 and PA ORFs were cloned into the pCDNA-3X-FLAG vector (generously provided by Dr. Andrew Mehle) which is a modified version of pcDNA3.1 (addgene) vector expressing proteins under CMV promoter. This vector contains three FLAG epitopes joined in tandem (3XFLAG) after the Notl site at its MCS followed by a Cytosine. This results in the expression of a protein having tri-alanine linker in between the individual ORFs and the C terminal 3X-FLAG tag. For the expression of untagged version of each $\mathrm{RdRp}$ subunit, the stop codon has been kept intact at the end of ORF. For the expression of V5 tagged NP, pcDNA3 vector has been modified in order to have glycine-glycine-serine-glycine linker in between the ORF and the C terminal V5 epitope tag. Briefly, two primers of 58 nucleotide length were annealed to create double-stranded piece of DNA having sticky ends on both sides (BamHI restriction site at the beginning of the sequence and the Notl site at the end of the sequence). The thermal protocol for ramp down annealing was as follows: $95 \circ \mathrm{C}$ for 5 minutes, 70 cycles of $95^{\circ} \mathrm{C}\left(-1^{\circ} \mathrm{C} / \mathrm{cycle}\right)$ each for 1 minute, followed by hold at $4 \circ \mathrm{C}$. The V5 linker was phosphorylated at 5 ' end by treatment with T4 Polynucleotide Kinase (PNK, Cat no. \# M0201S). The pcDNA3.1 (addgene) vector was digested with BamHI and Notl, treated with Calf alkaline phosphatase (CIP; NEB, Cat no. \#M0290S) and ligated with the $\mathrm{V} 5$ linker in $\mathrm{V}: \mathrm{I}=1: 20$ ratio.

Each individual insert fragment have been amplified using the cDNA template with the primers containing restriction enzyme overhangs. The PB2, PB1 and PA have been amplified with EcoRI and Notl overhang in two different PCR sets, one omitting the stop codon and the other including the stop codon in the reverse primer. The NP have been amplified using primers with Kpnl and BamHI overhangs. For each amplification, $50 \mu \mathrm{l}$ of PCR reaction consisted of $10 \mu \mathrm{l}$ of $5 \mathrm{x}$ Phusion HF buffer, $5 \mu \mathrm{l}$ each of the forward and reverse $5 \mu \mathrm{M}$ primers, $5 \mu \mathrm{l}$ of $2 \mathrm{mM}$ dNTPs, $5 \mu \mathrm{l}$ of cDNA template, $19.5 \mu \mathrm{l}$ sterile nuclease free water and $0.5 \mu \mathrm{l}$ of Phusion High-Fidelity DNA Polymerase. The modified pcDNA3-3X-FLAG have been digested with EcoRI \& Notl (NEB) and the pcDNA3-V5 vector has been digested with $\mathrm{Kpnl} \& \mathrm{BamHI}$, followed by treatment with CIP. The digested vectors as well as insert fragments were gel excised and ligated in a vector to insert ratio of 1:3 using T4 DNA ligase (Thermo Scientific ${ }^{\mathrm{TM}}$, Cat no. \# EL0011) as per manufacturer's protocol. $10 \mathrm{ul}$ of ligation mixture was transformed into DH5 alpha competent cells. Sequences of all the clones have been verified by sequencing.

\section{Transfection}

For examining protein expression level of each plasmid, HEK 293T cells were transfected using lipofectamine3000 (Invitrogen: Cat no. \# L3000015) as per manufacturer's instructions. All the plasmids were prepared using plasmid DNA isolation kit (Promega, Cat No. \# A1222). The 
223

224

225

226

227

228

229

230

231

232

233

234

235

236

237

238

239

240

241

242

243

244

245

246

247

248

249

250

251

252

253

254

255

256

257

258

259

260

261

262

263

264

265

266

267

268

269

270

271

272

273

pcDNA3.1 blank vector was used in the control cells. The media was changed 12 hours post transfection and incubated for 36 (or stated otherwise) hours following transfection.

\section{Western Blot}

Protein levels for transiently transfected cells were assessed by Western blotting. Transfected cells were lysed for 20 minutes in pre-chilled Co-Immunoprecipitation buffer $(50 \mathrm{mM}$ Tris- $\mathrm{HCl} \mathrm{pH}$ $7.4,150 \mathrm{mM} \mathrm{NaCl}, 0.53 \%$ NP-40) containing protease inhibitors (Roche-Sigma, Cat no. \# $11873580001)$ and phosphatase inhibitor and subsequently total protein samples were separated via $8 \%$ SDS-PAGE and transferred to polyvinylidene difluoride (PVDF, Bio-Rad, Cat no. \#1620177) membrane using transfer buffer (25 mM Tris, $191 \mathrm{mM}$ glycine, 0.025\% SDS \& 10\% methanol (vol/vol) in Trans-Blot Turbo Transfer System (Bio-Rad). After incubation with $5 \%$ nonfat milk in TBST ( $10 \mathrm{mM}$ Tris, $\mathrm{pH} 8.0,150 \mathrm{mM} \mathrm{NaCl}, 0.5 \%$ Tween 20) for $60 \mathrm{~min}$, the membrane was washed once with TBST and incubated with antibodies against 3xFLAG (1:5000, Sigma, Cat no.\# F3165 ), V5 (1:5000, CST, Cat no. \# D3H8Q), HA (1:5000, Cat no. \# C29F4), BNP (1:5000, generated in collaboration with BioBharati LifeScience Pvt. Ltd, India), at $4{ }^{\circ} \mathrm{C}$ for $12 \mathrm{~h}$. Membranes were washed with TBST three times for 5 minutes and incubated with a 1:25,000 dilution of horseradish peroxidase-conjugated anti-mouse (Sigma, Cat no. \# A9044-2ML6) or antirabbit (Sigma, Cat no. \# A0545-1ML) antibodies for $1 \mathrm{~h}$. Blots were washed with TBST three times for 5 minutes and developed with the ECL system (ThermoFisher, Cat No. \#34095) according to the manufacturer's protocols.

\section{Polymerase activity assay}

HEK293T cells were co-transfected with $94.11 \mathrm{ng}$ of each of the pcDNA3-PB2-FLAG, pcDNAPB1, $11.76 \mathrm{ng}$ of pcDNA-PA, $100 \mathrm{ng}$ of pcDNA3-BNP and $100 \mathrm{ng}$ of pHH21-vNA-Luc plasmids. The additional plasmids were used in various amount upto $150 \mathrm{ng}$ and is topped up by blank vector in order to keep the amount of DNA same in all the sets. In absence of additional plasmid, the total amount of RNP reconstitution plasmids were increased upto 500ng keeping the ratio of each RNP component same $\left(1 / 4^{\text {th }} \mathrm{BNP}, 1 / 4^{\text {th }} \mathrm{pHH} 21\right.$-vRNA-Luc, and the half of the total amount of DNA will be divided as 8:8:1 ratio for PB2, PB1 and PA). The transfection mix were prepared with Lipofectamine 3000 as per manufacturer's protocol using optiMEM (Thermo Scientific ${ }^{\mathrm{TM}}$, Cat no. \#31985-070). At 12 hours, the media was changed very carefully without dislodging any cell that may result in error in further signal. The cells were harvested at 36 hours (or as mentioned) post transfection and luciferase activity assay was performed using Promega Luciferase Assay System (Promega, \#E1500 \& \#E1910), as per manufacturer's protocol using luminometer (Promega Glomax 20/20).

\section{Ribavirin and Favipiravir dose-response assays in HEK 293T cells}

Ribavirin (Sigma-Aldrich, Cat no. \# R9644) was dissolved in water to prepare $80 \mathrm{mM}$ stock and Favipiravir (MedChemExpress, Cat no. \#HY-14768) was dissolved in DMSO to prepare a 200 $\mathrm{mM}$ stock which were aliquoted and stored at $-80^{\circ} \mathrm{C}$ until used. $0.2 \times 10^{6} \mathrm{HEK}$ 293T cells were seeded in 24-well plates and post 24 hours were treated with specified concentrations of ribavirin or favipiravir for $2.5 \mathrm{~h}$ at $37^{\circ} \mathrm{C}$ with $5 \% \mathrm{CO}$. Subsequently, cells were transfected with lipofectamine 3000 as per manufacturers protocol and incubated in fresh media containing specified concentrations of drugs were for 36 hours. Polymerase activity was then assayed as described above. The IC50 value was calculate by fitting the data to four parameter nonlinear equation.

\section{3-(4,5-Dimethylthiazol-2-yl)-2,5-diphenyltetrazolium Bromide (MTT) Assay}

30,000 HEK293T cells were seeded in 96-well plate. After 24 hours of seeding, the cells were treated with different concentrations of drugs in triplicates for 36 hours. Post-treatment, $100 \mu \mathrm{L}$ of MTT reagent $(5 \mathrm{mg} / \mathrm{mL}, \mathrm{SRL})$ dissolved in phosphate-buffered saline (PBS) was added to the 
274

275

276

277

278

279

280

281

282

283

284

285

286

287

288

289

290

291

292

293

294

295

296

297

298

299

300

301

302

303

304

305

306

307

308

309

310

311

312

313

314

315

316

317

318

319

cells and incubated for $3 \mathrm{~h}$ at $37^{\circ} \mathrm{C}$. Subsequently, the reagent was removed and the formazan crystals were dissolved by adding $100 \mu \mathrm{L}$ of dimethyl sulfoxide (DMSO) (Sigma) in each well. The absorbance of the suspension was measured at $595 \mathrm{~nm}$ using an Epoch 2 microplate reader (BioTek Instruments). The percentages of metabolically active cells were compared with the percentage of control cells treated with vehicle control.

\section{Transfection-Infection assay}

$0.1 \times 10^{6} \mathrm{HEK} 293 \mathrm{~T}$ cells were seeded in 48-well plates. After 20 hours of seeding, the cells were transfected with $0.25 \mathrm{ug}$ of reporter plasmid using lipofectamine 3000 and 22 hours post transfection, the cells were pre-treated with half-maximal inhibitory concentrations (IC50) of the drugs (Ribavirin:18.54 uM; Favipiravir:25.46 uM) for $2.5 \mathrm{~h}$ at $37^{\circ} \mathrm{C}$ with $5 \% \mathrm{CO}$. Following 2.5 hours of treatment, the cells were infected with Influenza B virus at an $\mathrm{MOI}$ of 0.1 in presence of drugs and the polymerase activity was assayed at 16 hours of post infection.

\section{Statistical analysis}

The arithmetic mean and standard deviation of the firefly luciferase signal were calculated from three biological replicates for each experiment. The data were plotted in bar diagram with standard deviations as error bars. For dual luciferase assay, the firefly luciferase signal was normalized with the Renilla luciferase signal for each replicate. In firefly luciferase assays involving the host factors, viral factors, and antiviral molecules and dual luciferase assays; normalized mean and standard deviation were calculated against the control. The normalized mean was calculated by dividing the arithmetic mean of the experimental sets by the mean of the control set and converting it to a percentage value. Normalized standard deviation was calculated by normalizing the coefficient of variations against the control and augmenting it with the normal mean. A two-tailed Student's T-test was performed for comparison of the data sets.

\section{Results:}

\section{Generation of influenza B virus reporter plasmid for expression of viral reporter RNA in mammalian cells}

In order to establish a reporter based RNP activity assay, a template RNA harboring the reporter gene flanked by the viral UTRs needs to be expressed under the control of RNA polymerase I promoter. This ensures that the reporter RNAs are devoid of any 5'- or 3'- terminal modifications, hence mimicking authentic viral genomic RNA. To achieve this, firstly we have constituted the "insert" harboring the firefly luciferase gene in reverse orientation flanked by viral 5'- and 3'- UTRs. Subsequently, this cassette was introduced into the pHH21 vector in between the RNA polymerase I promoter and terminator. The entire process of constituting authentic viral UTRs, assembling them with the reporter gene and introducing this cassette into the $\mathrm{pHH} 21$ vector utilized a single DNA polymerase enzyme without the need of any restriction enzyme or specialized kits (Figure 1).

Viral genomic RNA, purified from influenza B/Brisbane/60/2008 virus particles (Figure $1 \mathrm{~A}$ ), was used as a source for the amplification of the 144nt 5'- and 95nt 3'-UTRs, using sequence specific primers with 15-20 nucleotide overhanging sequences corresponding to the vector and the reporter gene (Figure 1B, 2A). The resulting PCR products thus contain (i) viral 5'-UTR flanked by the overlapping sequences with the Pol-I promoter and 3'-termini of the reporter gene and (ii) viral 3' UTR region flanked by the overlapping sequence with 5'-termini of reporter gene and PolI terminator. These double-stranded PCR products were then used as primers to amplify the 
firefly luciferase gene from the pHH21-vNA-Luc plasmid, kindly provided by Prof. Andrew Mehle, University of Wisconsin Madison (Figure1C, 2B). The final PCR product, constitutes reporter gene flanked by viral 5'- and 3'- UTR regions along with partial sequences from the Pol-I promoter and terminator regions at the extreme 5'- and 3'- termini respectively. In order to synthesize the final reporter plasmid construct, named as pHH21-BNA-Luc, this cassette was inserted into the $\mathrm{pHH} 21$ vector (amplified in a separate PCR reaction; Figure 2C) using the Circular Polymerase Extension Cloning (CPEC), as originally described by Quan et al[33, 34] (outlined in the Figure 1D). A vector to insert molar ratio of 1:3 generated maximum amount of assembled product (Figure 2D). Reaction product was transformed in chemically competent $E$. coli and successful incorporation of the insert was confirmed by the colony PCR screening method. All the PCR amplifications were performed using a single Phusion High-Fidelity DNA polymerase as described in further detail in the methods section.

To reconstitute functional reporter RNPs inside the cells, reporter RNA template needs to be coexpressed with NP and the RdRp subunits, PB1, PB2 and PA (Figure 1E, F). The RdRp subunits were cloned into the pCDNA-3X-FLAG vector (generously provided by Dr. Andrew Mehle) under the control of CMV promoter with the help of EcoRI and Notl restriction enzymes, which results in incorporation of a tri-alanine linker in between the individual ORFs and the three FLAG epitopes joined in tandem (3X-FLAG). For expression of untagged proteins, ORFs with the stop codon were cloned using the same strategy. The NP gene was cloned into a modified pcDNA3 vector harboring V5 epitope tag (mentioned in the methods section) with the help of the Kpnl and BamHI sites, with a glycine-glycine-serine-glycine linker in between the ORF and the V5 epitope tag.

\section{Standardization of influenza B virus RNP activity assay}

Influenza B virus reporter RNPs were reconstituted in HEK293T cells through transient transfection of the reporter plasmid (pHH21-BNA-Luc) either in the absence (negative control) or the presence of the plasmids expressing PB1, PB2, PA and NP proteins (Figure 3A). Cells were harvested at 24 hours of post-transfection and luciferase activity was measured to quantitate the Influenza B RNP activity. To our surprise, the positive control set showed only $10^{\wedge} 4$ signal (luciferase light unit or RLU) which is only two log higher than the negative control set (10^2 RLU), suggesting suboptimal activity of the reconstituted RNPs. This could be due to the poor expression levels of the RdRp subunits, PB1 and PB2, in comparison to the PA and NP proteins, as observed from the western blot analysis using specific antibodies, hence prohibiting the successful assembly of reporter RNPs inside the cell. To investigate this further, we examined the sequence of the constructs carefully and noticed that all of the protein expression plasmids lack the Kozak sequence which may result in their suboptimal translation. The PA gene have a Guanosine after the ATG sequence which is a part of Kozak sequence. PB1 and PB2 do not have this Guanosine after the start codon ATG. Thus half Kozak sequence is conserved in PA gene 
A

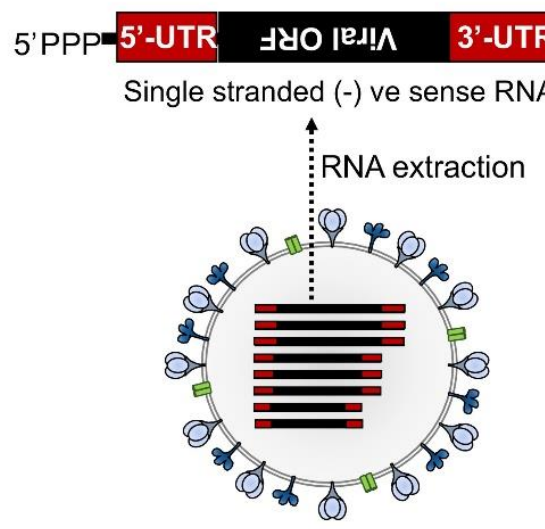

E

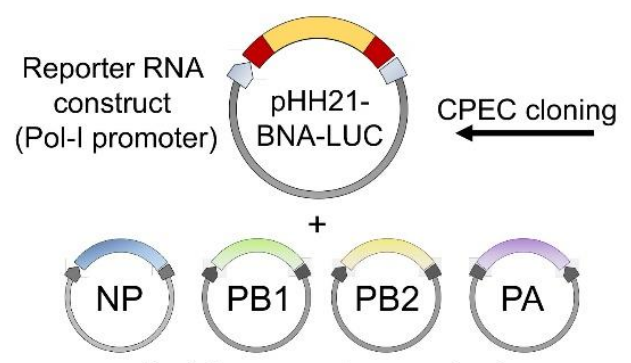

Protein expression constructs

(CMV promoter)
B

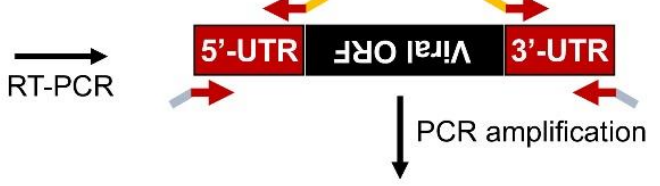

C Generation of UTRs with

terminal overhangs

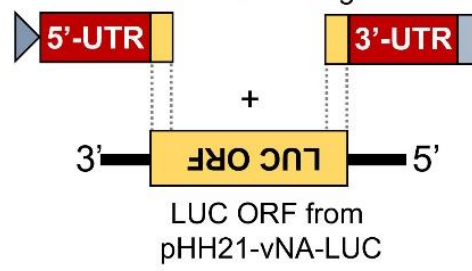

PCR amplification of LUC ORF using UTRs with terminal overhangs

Reporter cassette with LUC ORF flaked by viral UTRs and terminal overhangs
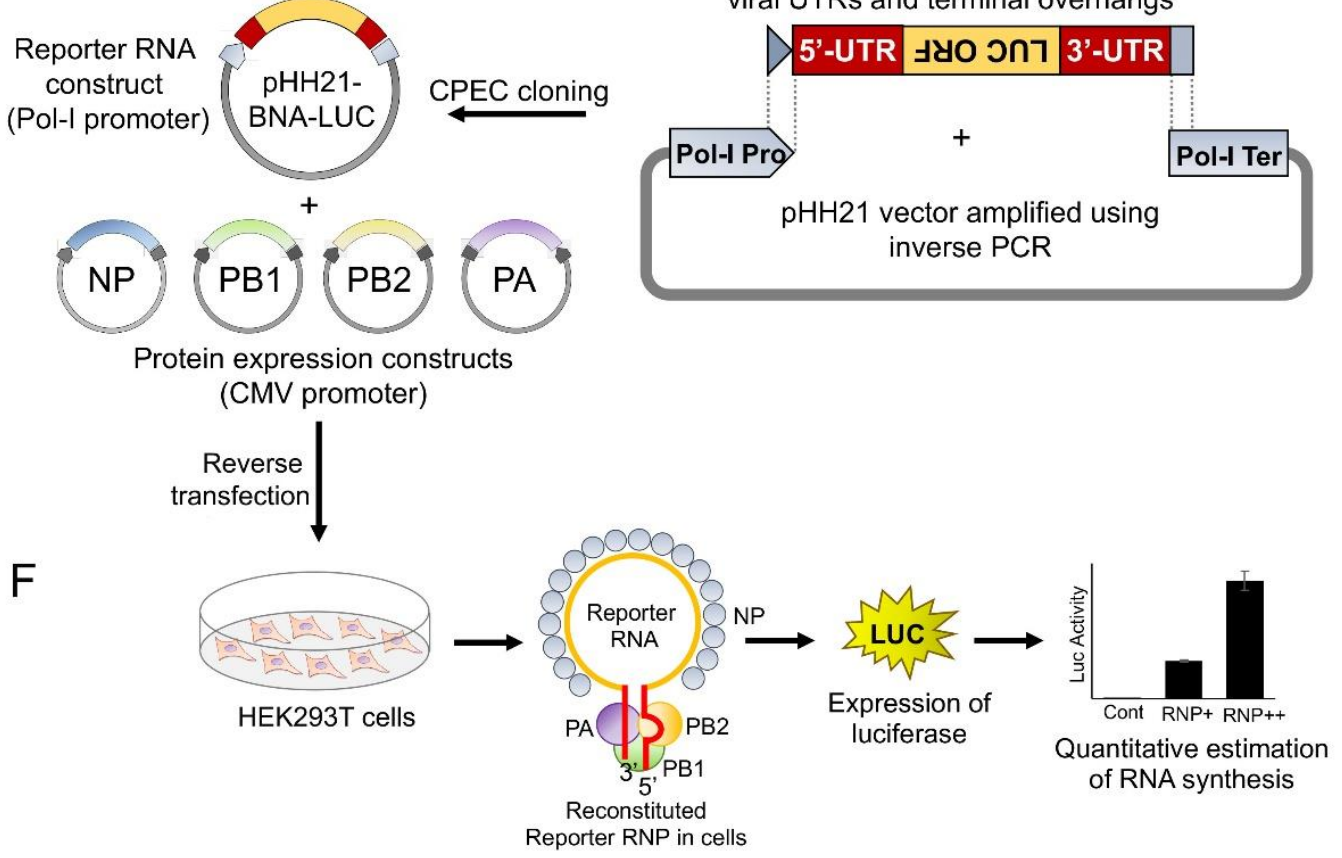

Figure 1: An illustrative overview of cloning strategy of influenza $B$ reporter plasmid and reporter assay (A) Total RNA was isolated from amplified stocks of Influenza B/Brisbane/60/2008 virus (B) total RNA was converted to cDNA by performing RT-PCR and 5' \& 3' UTRs were amplified using specific primers containing overhangs. (C) The doublestranded 5' and 3' UTRs containing overlapping regions were used as primers to amplify the luciferase ORF. (D) The resulting PCR product was used as an insert for CPEC assembly with the PCR amplified vector fragment. (E-F) The generated reporter and other protein expressing plasmids upon co-transfection in HEK293T cells reconstitute the luciferase RNP's that express luciferase enzyme under the control of the viral promoter. The quantification of the luciferase signal gives the measure of viral polymerase activity. 
To address this, we performed site-directed mutagenesis to introduce partial Kozak sequences in each of these plasmids without any alteration in the ORF and repeated the polymerase activity assay with them. As evident from figure $3 \mathrm{~A}$, the introduction of the Kozak sequence significantly boosted the expression of all of the RNP proteins which together resulted in reporter activity of $10^{\wedge} 6 \mathrm{RLU}$, four logs higher than the negative control set. Interestingly, the expression levels of the PA subunit still remained severalfold higher than the other two subunits of RdRp, PB1 and PB2 (Figure 3A).
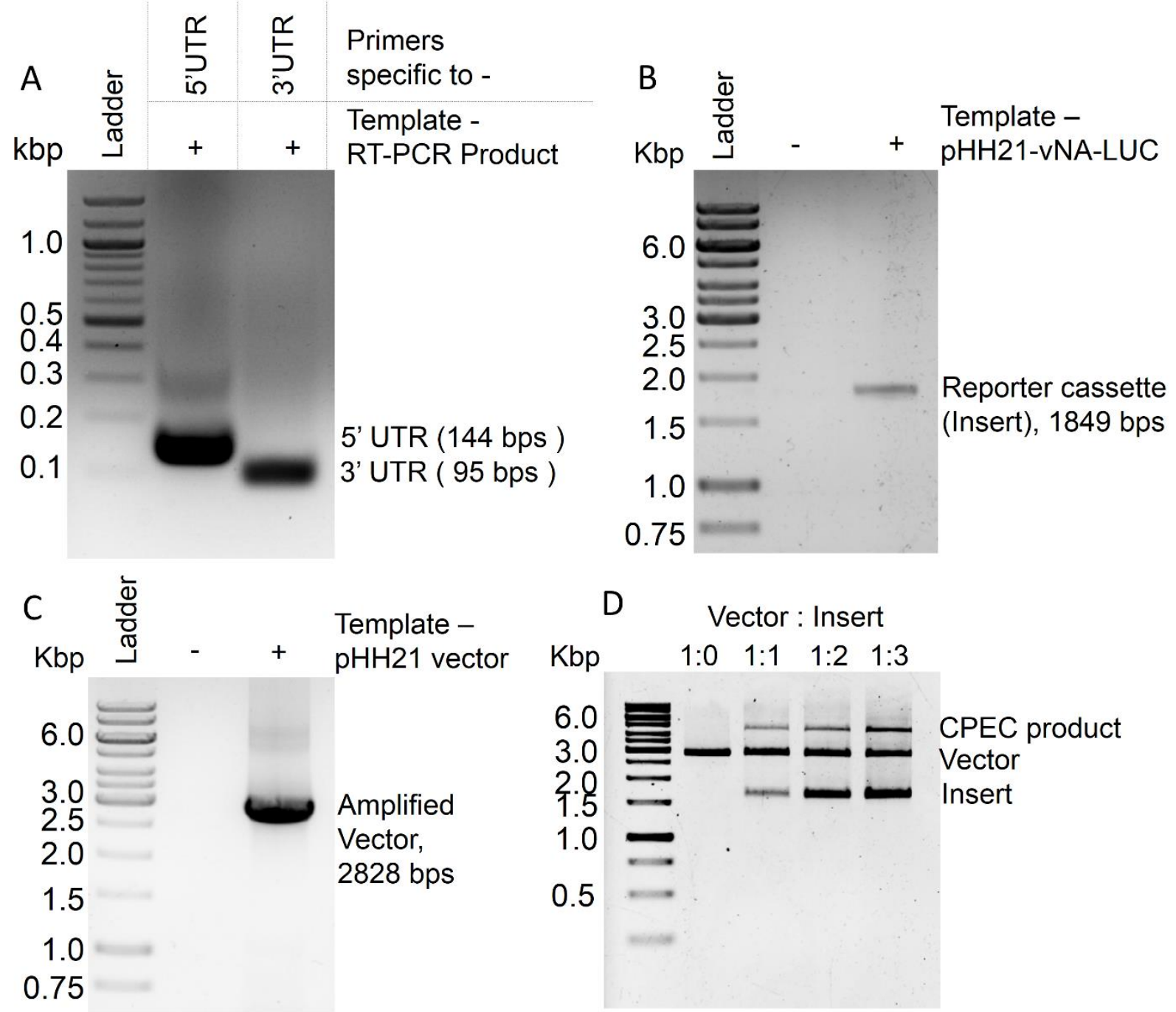

Figure 2: $P C R$ amplification and CPEC reaction for construction of reporter construct: Agarose gel electrophoresis images of (A) PCR amplification products corresponding to the 5'UTR and 3'UTR of NA-NB segment. (B) PCR amplification product of luciferase ORF using double-stranded PCR products corresponding to 5' and 3' UTRs as primers. (C) PCR amplification of pHH21 vector. (D) CPEC products with different ratio of vector to insert.

Precise abundance of the PB1, PB2 and PA subunits in equimolar amounts is a pre-requisite for the successful assembly of the heterotrimeric RdRp complex and hence, reconstitution of reporter RNPs to optimum levels. Therefore, we tried to optimize the amount of the plasmids to be transfected in order to have a comparable expression of the RdRp subunits. Reporter RNPs were 
reconstituted using different ratios of RdRp subunit plasmids, while keeping the amount of the reporter RNA and NP plasmid constant. As shown in Figure 3B, increasing the amount of PB1 and PB2 expressing plasmids compared to the PA led to a gradual increase in reporter activity and a ratio of 8:8:1 for PB1: PB2: PA resulted in comparable expression of all three polymerase subunits and maximum reporter activity. Subsequently, keeping the ratio of the polymerase subunit plasmids constant, we increased the amount of the NP expressing plasmid, which resulted in increase in the reporter activity, hence stretching the sensitivity of this reporter assay to the maximum level (Figure $3 \mathrm{C}$ ). The NP to polymerase proportion up to $1: 2$ results in increase in polymerase activity. Further increase in the amount of NP does not result in substantial increase in polymerase activity. Hence for our further experiments, we have used this ratio of RNP reconstituting plasmids. Once we optimize the amounts of various plasmids reconstituting reporter RNPs, we have performed a time kinetics experiment in order to assess the optimum time required to obtain a signal of $10^{\wedge} 6 \mathrm{RLU}$ or more (Figure 3D).
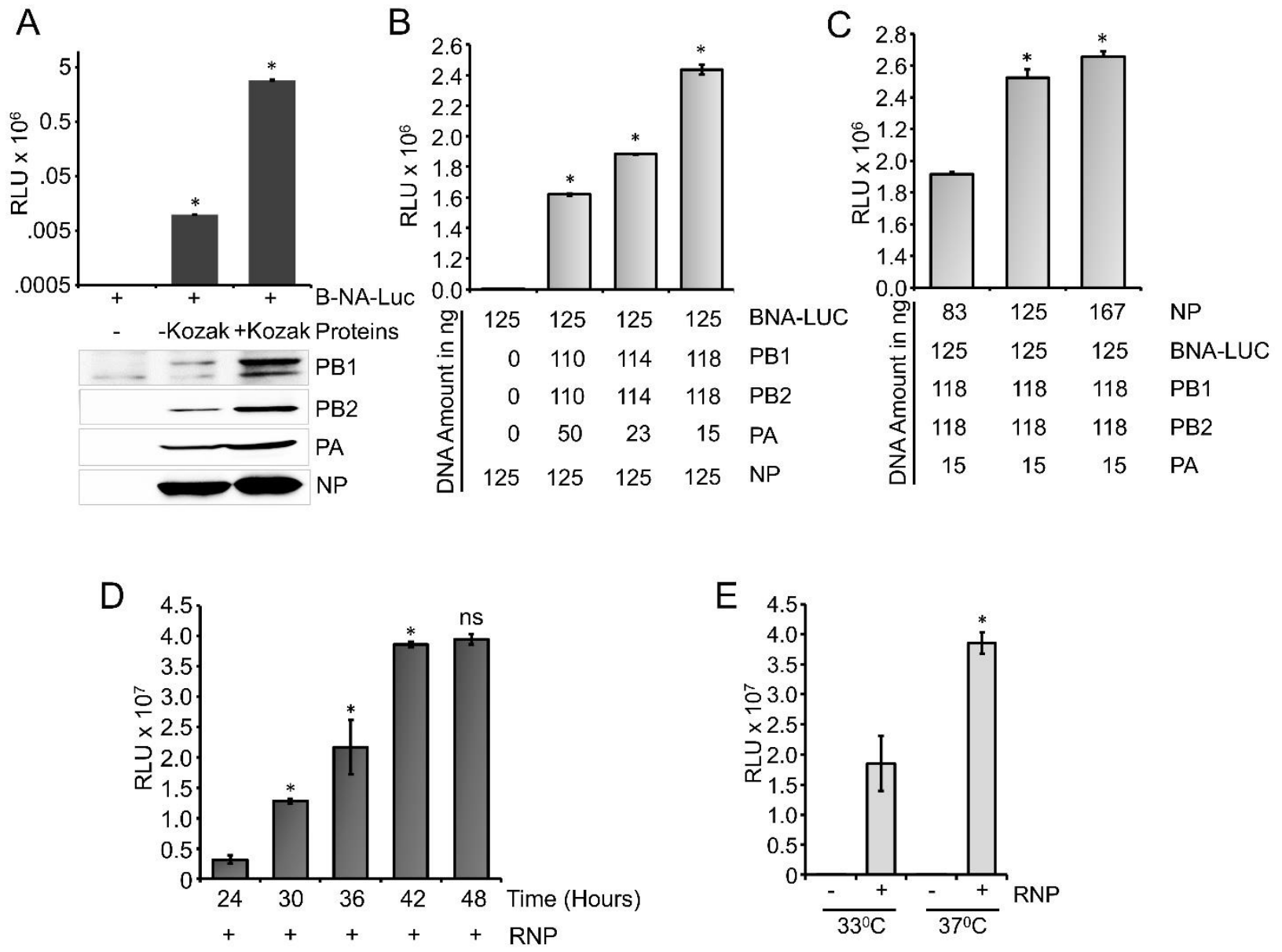

Figure 3: Optimization of the reporter system: (A) Effect of Kozak sequence on expression of viral polymerase proteins and influenza B RNP activity assay (B) Reporter RNP activity assay with different ratio of PA protein expression plasmid with respect to PB1 and PB2. (C) Reporter RNP activity assay with various amount of NP expression plasmid. (D) 
assay ( $n=3 \pm$ standard deviation, ${ }^{*} p<0.05$ one-way ANOVA with post hoc Student's t-test when compared to the preceding set, for Figure E, comparison was performed in between two RNP positive sets, ns = not significant).

403 A time dependent increase in the reporter activity was observed which reaches a plateau by 42 hours of post transfection. Additionally, influenza B polymerase activity was assessed at different temperatures $\left(33^{\circ} \mathrm{C}\right.$ and $\left.37^{\circ} \mathrm{C}\right)$ by reconstituting the polymerase through transient transfection at $37^{\circ} \mathrm{C}$ for 12 hours followed by an additional incubation of 30 hours at respective temperatures (Figure 3E). As observed at $37^{\circ} \mathrm{C}$, reporter activity was almost two fold higher than the activity at $33^{\circ} \mathrm{C}$, a data corroborated perfectly with the previous results obtained by Santos et al[35]. Together, we present a fast sensitive and high throughput reporter assay for monitoring influenza $B$ virus RNA synthesis in an infection free setting.

All of the assays were performed in 24, 48 and 96 well plates, in triplicates for each of the biological sets (data presented in this manuscript is from 24 well plates), hence confirming that this assay system is high-throughput compatible. Additionally, five log difference between the signal and background readouts provides a wide dynamic range for this reporter based assay system. Together, we have been able to establish a fast, reliable and high-throughput compatible assay system for monitoring influenza B virus RNP/ polymerase activity, which is suitable for assessing the effect of various viral or cellular factors in modulating RNP activity and hence viral RNA synthesis.

The influenza B RNP activity assay is suitable for evaluating the efficacy of viral or host factors in regulating viral RNA synthesis.

To this end, we set out to evaluate the efficacy of the newly developed polymerase activity assay in identifying novel viral and host factors that may regulate viral RNA synthesis. Influenza virus Nonstructural Protein 1 (NS1) is a multifunctional protein participating mainly in the suppression of antiviral defense mechanisms exerted by a wide variety of host factors [36, 37]. Additionally, influenza A virus NS1 protein has been shown to boost viral RNA synthesis[38-40], possibly through interfering with antiviral activity DDX21 and RAP55 [41, 42]. While the immune suppression activity of influenza B NS1 was well studied[37, 43, 44], little is known about the role of NS1 in regulating influenza B virus RNA synthesis. Hence, we evaluated the ability of influenza $B$ virus NS1 protein to promote viral RNA synthesis with the newly developed reporter RNP activity assay. Influenza B virus NS1 ORF was cloned into the PCDNA-3X-FLAG vector that resulted in the expression of the C-terminally FLAG tagged NS1 protein. Influenza B reporter RNPs were reconstituted in HEK293T cells either in the absence or presence of increasing amounts of NS1 protein and reporter activity was monitored to assess the extent of viral RNA synthesis. Increasing amount of NS1 resulted in 1.5 to 2 folds increase in reporter activity (Figure 4A) establishing it as a positive regulator of viral RNA synthesis. Furthermore, reconstituting reporter RNPs in the presence of NS1 presents an assay system that closely resembles RNA synthesis, which occurs during the course of infection.

438 Subsequently, we tested the ability of a host factor to regulate influenza B virus RNA synthesis using our reporter RNP activity assay. Host Protein Kinase C, specifically the delta isoform, has 440 been shown to positively influence influenza A virus RNA synthesis by regulating the 441 phosphorylation and subsequent assembly of viral nucleoproteins into RNPs. Interestingly, the 442 constitutively active catalytic domain of PKC delta (PKCD), when overexpressed, negatively 
regulates influenza A virus RNA synthesis [45]. To determine the role of PKCD in regulating influenza B virus RNA synthesis we employed the newly developed reporter RNP activity assay. As evident from figure $4 \mathrm{~B}$, increasing amounts of PKCD resulted in a gradual decrease in RNP activity and hence viral RNA synthesis without any severe impact upon the translation of viral proteins. These data not only substantiates the role of PKCD in regulating influenza B virus RNP activity, but also validates the efficacy of our assay system in studying the effect of pro- or antiviral factors regulating viral RNA synthesis.

A

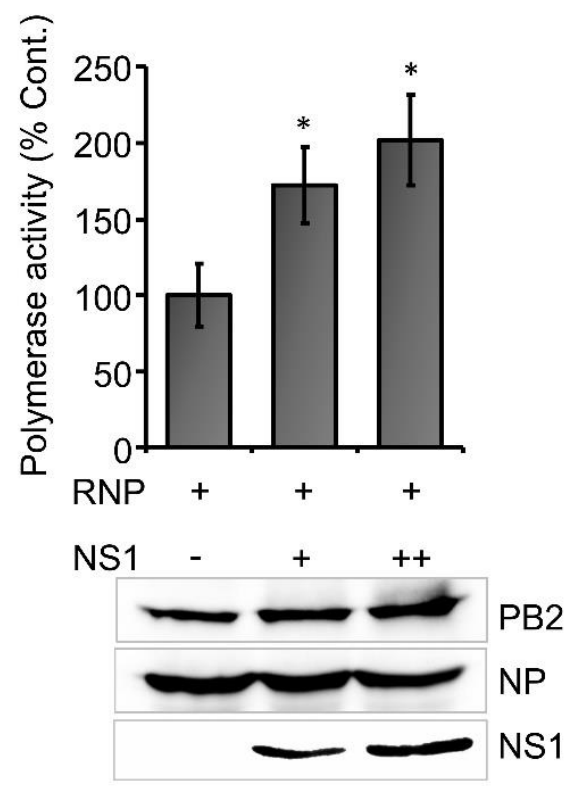

B

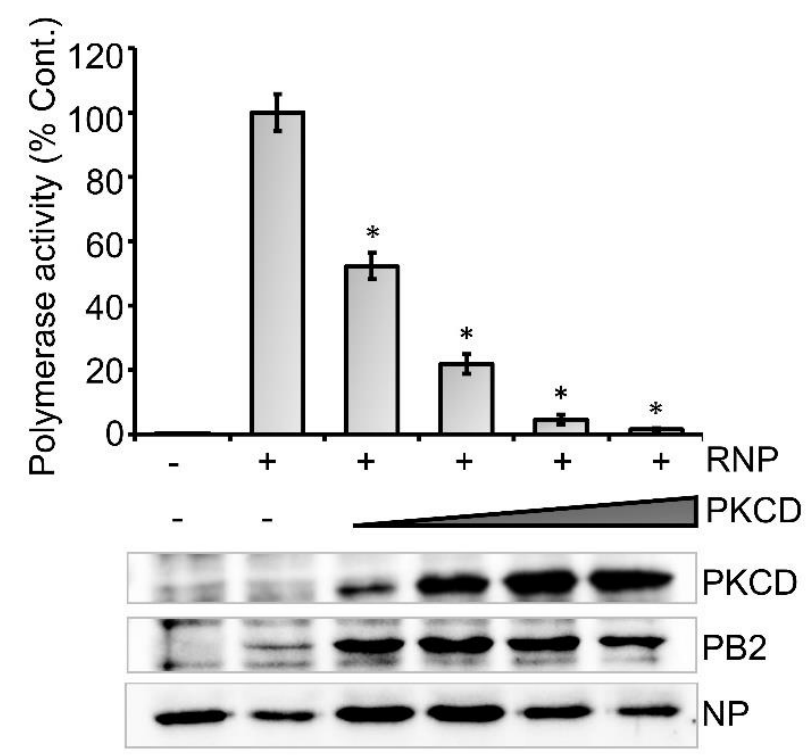

Figure 4: Effect of host \& viral factors upon viral RNA synthesis: (A) Effect of an increasing amount of viral NS1 protein (PKCD) protein on B RNP activity assay. ( $n=3 \pm$ standard deviation. ${ }^{*} \mathrm{p}<0.05$ one-way ANOVA with post hoc student's t-test when compared to the preceding set. drugs.

Finally, we intend to establish the suitability of the RNP activity assay as a high throughput screening platform of antiviral drugs that can inhibit viral RNA synthesis and hence virus replication. Ribavirin and Favipiravir are nucleoside (purine) analogues, which inhibit the replication of a wide variety of RNA viruses by acting as an alternative substrate for viral RNA polymerase[46, 47]. Additionally, Ribavirin also inhibits inosine monophosphate 
A
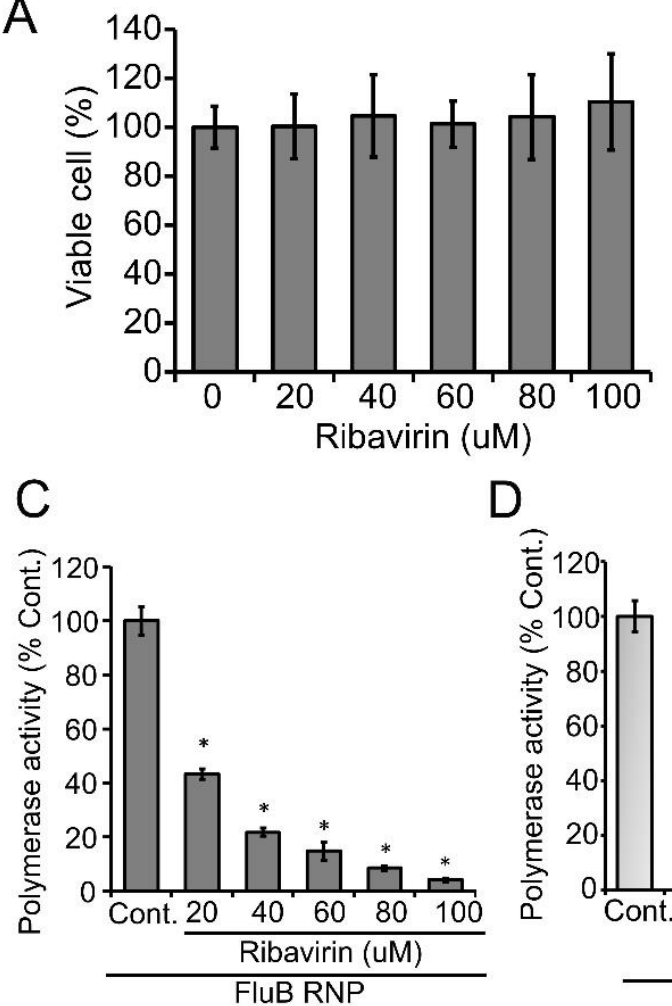

D

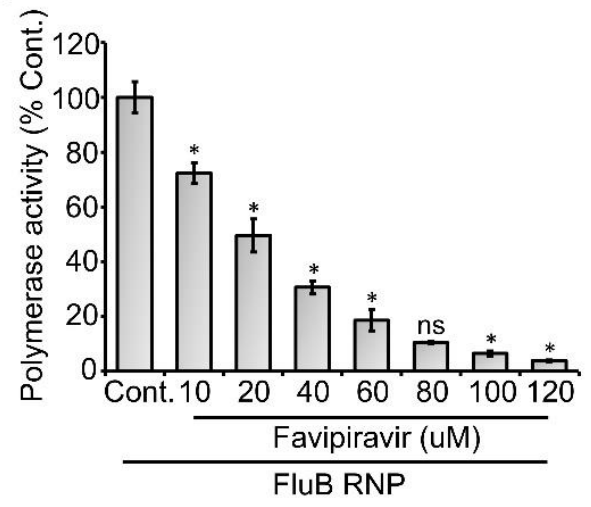

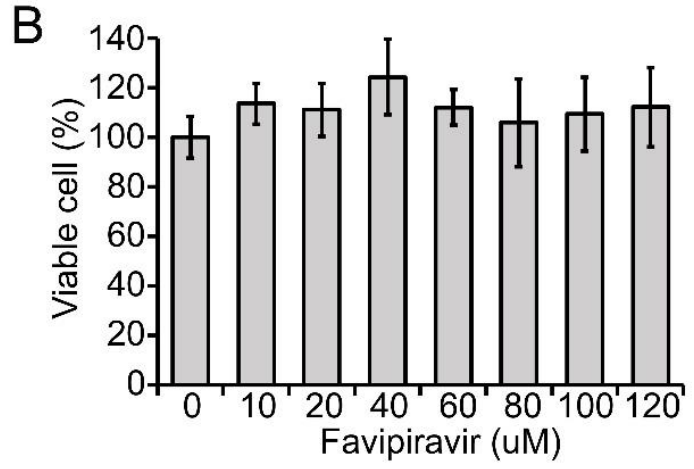

$\mathrm{E}$

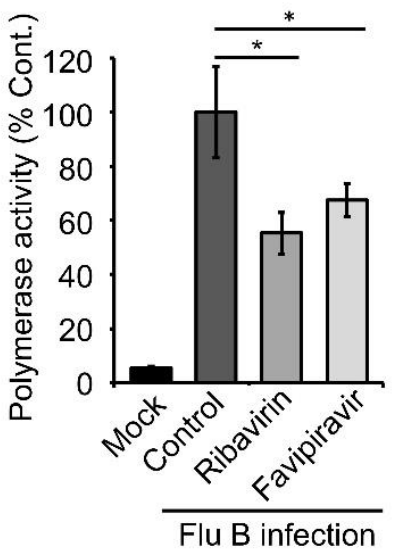

462

463

464

465

466

467

468

469

470

471

472

473

474

475

476

477

478

479

480

481

482

Figure 5: Effect of antiviral drugs upon viral RNA synthesis in infection-free and infection setting: (A, B) MTT assay to determine the cytotoxicity of Ribavirin and Favipiravir on HEK293T cells. (C, D \& E) Effect of Ribavirin and Favipiravir on influenza B virus RNP activity. Viral polymerase proteins in HEK293T cells are expressed either by transient transfection (C, D) or by infecting the cells with Influenza B virus $(E)$. ( $n=3 \pm$ standard deviation, ${ }^{*} p<0.05$ one-way ANOVA with post hoc Student's t-test when compared to the preceding set, for Figure E, comparison was performed with control set, $\mathrm{ns}=$ not significant).

dehydrogenase thereby depleting the GTP and creating an imbalance in the nucleotide pool inside the cell[48]. Both Ribavirin and Favipiravir has been approved as chemoprophylaxis as well as therapy against influenza $A$ and $B$ viruses[49-51]. Hence, we used these two drugs as positive controls to test the efficacy of our assay system for antiviral screening. MTT assay was performed in HEK293T cells (Figure 4A, B), where neither of the drugs show any cytotoxicity. HEK293T cells were pretreated with different concentrations of the drugs followed by forward transfection to reconstitute the influenza B reporter RNPs and subsequent incubation with the drugs for 36 hours. Reporter activities were measured and expressed as relative percentages with respect to the vehicle control. Data presented in Figure $5 \mathrm{C}$, D, shows a dose-dependent decrease in the reporter activity and hence viral RNA synthesis with increasing amounts of the drugs with IC50 values of $18.54 \mathrm{uM}$ and $25.46 \mathrm{uM}$ for Ribavirin and Favipiravir respectively.

To further extend the scope of the assay system, we sought to check if this system is capable of assessing the effect of host factors or antivirals upon the overall progress of infection. For this purpose, we transfected HEK293T cells with the reporter construct and subsequently infected 
them with influenza B virus at 20 hours post transfection. It is expected that in infected cells reporter RNA template will get transcribed with the help of RdRp and NP proteins expressed from viral genomic RNA segments. As evident from Figure 5E, infected cells supported successful generation of reporter RNPs and hence showed high reporter activity, while the uninfected cells showed no such effect. Interestingly, when parallel set of cells were treated with Ribavirin and Favipiravir prior to infection with Influenza B virus, significant reduction in reporter activity were observed, hence suggesting an overall reduction in viral gene expression and hence virus replication in presence of the drugs. Together our data reconfirms the activity of the two well established antiviral drugs against influenza B virus RNA synthesis machinery and also establishes the newly developed reporter based influenza B virus RNP activity assay as a high throughput screening platform of antivirals specifically inhibiting viral RNA synthesis.

\section{Discussion:}

Luciferase based reporter assay systems remain a key tool for analyzing gene expression in a wide variety of organisms; viruses are not exceptions. While, for positive sense RNA viruses, introduction of the single sub-genomic reporter RNA template in cells is sufficient for expression of reporter genes; for negative sense RNA viruses, RNP associated viral proteins needs to be synthesized along with the reporter RNA in order to reconstitute complete RNPs, which then leads to the expression of reporter enzyme as a proxy of viral genes[12, 52, 53]. This is why, successful reconstruction of reporter viral RNPs require extensive cloning of multiple RNA and protein expressing constructs, standardization of their expression in right stoichiometric ratios and optimization of other crucial parameters like time, temperatures etc. Although, several groups have reported reporter assay systems for monitoring influenza $A$ and $B$ virus RNA synthesis, nonavailability of detailed methodical description makes the process of establishing the assay system non-trivial[12, 13, 24-26]. In this work, we have established a firefly luciferase-based influenza B virus RNP activity assay and presented the detailed methodology of the entire procedure which could be easily followed for the development of such viral and non-viral reporter assay systems.

We have introduced a unique cloning strategy for the construction of the influenza B virus reporter RNA construct that is devoid of restriction enzymes or any other specialized enzymes. This cloning strategy utilizes a single DNA polymerase, which is widely used for regular molecular biology work and hence easily available. Using this polymerase, two consecutive PCR amplification reactions led to the generation of the reporter RNA cassette encompassing the reporter ORF flanked by viral 5'- and 3'-UTR regions which were then inserted into the vector using CPEC cloning method. While the vector and the insert used for CPEC, are also compatible for Gibson assembly based cloning method, we intentionally avoided use of any specialized enzymes to make the overall procedure simple and user-friendly that could be adapted for cloning of any other reporter RNA constructs. In addition to reporter RNA construct, we also cloned ORFs corresponding to viral PB1, PB2, PA and NP proteins and optimized their expression to reconstitute reporter RNPs at maximum levels. The robustness of this assay system was substantiated by testing the efficacy of antiviral drugs, Ribavirin and Favipiravir, to inhibit influenza $B$ virus RNA synthesis either in the context of reconstituted RNPs (through transfection) or during the course of infection. The fact that the reporter RNA template can be preferentially recognized 
525 by viral NP and RdRp subunits to reconstitute reporter RNPs during the course of infection, confirms that the reporter RNA mimics viral genomic RNA segments and hence validates its suitability to be used for the study of viral RNA synthesis and effect of various viral and host factors upon the same. In fact, using the newly developed reporter RNP system, we for the first time showed that viral NS1 protein can boost influenza B virus RNA synthesis and constitutively active form of host PKCD can downregulate the same. While effect of NS1 and PKCD proteins has been previously characterized in case of influenza A virus[38-40, 45], our results substantiates that these proteins participate similarly regulate influenza $B$ virus RNA synthesis as well.

534 Altogether, we present a comprehensive roadmap for development, characterization and validation of a reporter-based Influenza B virus polymerase/ RNP activity assay and made it generic enough to be followed by others who intend to develop similar assay systems for influenza and other negative sense RNA viruses. We also made all the resources publicly available (upon request) to enrich the armoury for combating influenza $B$ viruses and hope that it will be widely utilized to identify new therapeutic strategies against this deadly human pathogen.

Table 1. Primers used in this study.

\begin{tabular}{|c|l|}
\hline Name of the primer & Sequence (5' ->3') $^{\prime}$ \\
\hline Uni 9 & AGCAGAAGC \\
\hline NA-NB_F & AGTAGTAACAAGAGCATTTTTCAG \\
\hline NA-NB_R & AGCAGAAGCAGAGCATC \\
\hline 5' UTR_F & CATTTTGGGCCGCCGGGTTATTAGTAGTAACAAGAGCATTTTTCAG \\
\hline 5' UTR_R & CGGAAAGATCGCCGTGTAATGGAGGAATGGTTGAGTC \\
\hline 3' UTR_F & CTTTATGTTTTTGGCGTCTTCCATTGTTCATTTTTGGCCTATTTG \\
\hline 3' UTR_R & CCTCCGAAGTTGGGGGGGAGCAGAAGCAGAGCATCTTC \\
\hline PHH21_F & CCCCCCCAACTTCGGAGG \\
\hline PHH21_R & AATAACCCGGCGGCCCAAAATG \\
\hline PHH21_SEQ2 & AAAACGCTGGGCGTTAATCAAAGAGGCG \\
\hline PHH21SEQ1 & GGGGGACACTTTCGGACATCTGGTC \\
\hline pcDNA3-V5 For & GATCCGGAGGTAAGCCTATCCCTAACCCTCTCCTCGGTCTCGATTCTACGTAGTAAGC \\
\hline PcDNA3-V5 Rev & GGCCGCTTACTACGTAGAATCGAGACCGAGGAGAGGGTTAGGGATAGGCTTACCTCC \\
\hline NP_For & ATTCGGGGTACCGCCACCATGTCCAACATGGATATTGACG \\
\hline NP_Rev_V5 & ATTCGCGGATCCACCATAATCGAGGTCATCATAATCCTC \\
\hline NP_Rev_Stop & ATTCGCGGATCCTTAATAATCGAGGTCATCATAATCCTC \\
\hline PB1_For & TAAGCGGAATTCACCATGAATATAAATCCTTATTTTCTCTTC \\
\hline PB1_Rev_FLAG & ATTGAGGCGGCCGCTATGTACCCAATCTCACCAAG \\
\hline PB1_Rev_Stop & ATTGAGGCGGCCGCTTATATGTACCCAATCTCACC \\
\hline PB2_For & TAAGCGGAATTCACCATGACATTGGCCAAAATTGAATTG \\
\hline PB2_Rev_FLAG & ATTGAGGCGGCCGCGCTCAAGGCCCACCCC \\
\hline PB2_Rev_Stop & ATTGAGGCGGCCGCTTAGCTCAAGGCCCACCC \\
\hline PA_For & TAAGCGGAATTCACCATGGATACTTTTATTACAAGAAACT \\
\hline PA_Rev_FLAG & ATTGAGGCGGCCGCTTCGTCCATAATCTCGTC \\
\hline PA_Rev_Stop & ATTGAGGCGGCCGCTTATTCGTCCATAATCTCGTC \\
\hline
\end{tabular}


542 Table 2: PCR conditions used in the study for amplification of individual inserts.

\begin{tabular}{|c|c|c|c|c|c|c|}
\hline $\begin{array}{l}\text { PCR } \\
\text { amplification }\end{array}$ & $\begin{array}{l}\text { Forward } \\
\text { Primer }\end{array}$ & $\begin{array}{l}\text { Reverse } \\
\text { Primer }\end{array}$ & $\begin{array}{l}\text { Denaturation } \\
\text { (temp./duration) }\end{array}$ & $\begin{array}{l}\text { Cyclic } \\
\text { denaturation, } \\
\text { annealing and } \\
\text { elongation } \\
\text { (temp./duration) }\end{array}$ & $\begin{array}{l}\text { No. of } \\
\text { cycles }\end{array}$ & $\begin{array}{l}\text { Final } \\
\text { elongation }\end{array}$ \\
\hline $\begin{array}{l}\text { NA-NB } \\
\text { fragment }\end{array}$ & NA-NB_F & NA-NB_R & $98^{0} \mathrm{C} / 30$ seconds & $\begin{array}{l}98^{\circ} \mathrm{C} / 10 \text { seconds } \\
60^{\circ} \mathrm{C} / 30 \text { seconds } \\
72^{\circ} \mathrm{C} / 95 \text { seconds }\end{array}$ & 35 & $72^{\circ} \mathrm{C} / 5$ minutes \\
\hline 5' UTR & 5' UTR_F & 5' UTR_R & $98^{\circ} \mathrm{C} / 30$ seconds & $\begin{array}{l}98^{\circ} \mathrm{C} / 10 \text { seconds } \\
60^{\circ} \mathrm{C} / 25 \text { seconds } \\
72^{\circ} \mathrm{C} / 5 \text { seconds }\end{array}$ & 35 & $72^{\circ} \mathrm{C} / 5$ minutes \\
\hline 3' UTR & 3' UTR_F & 3' UTR_R & $98^{\circ} \mathrm{C} / 30$ seconds & $\begin{array}{l}98^{\circ} \mathrm{C} / 10 \text { seconds } \\
59^{\circ} \mathrm{C} / 25 \text { seconds } \\
72^{\circ} \mathrm{C} / 5 \text { seconds }\end{array}$ & 35 & $72^{\circ} \mathrm{C} / 5$ minutes \\
\hline $\begin{array}{l}\text { Insert for } \\
\text { Reporter } \\
\text { plasmid }\end{array}$ & $\begin{array}{c}\text { 5' UTR } \\
\text { double- } \\
\text { stranded } \\
\text { PCR product }\end{array}$ & $\begin{array}{l}\text { 3' UTR } \\
\text { double- } \\
\text { stranded } \\
\text { PCR } \\
\text { product }\end{array}$ & $98^{\circ} \mathrm{C} / 30$ seconds & $\begin{array}{l}98^{\circ} \mathrm{C} / 10 \text { seconds } \\
72^{\circ} \mathrm{C} / 80 \text { seconds }\end{array}$ & 35 & $72^{\circ} \mathrm{C} / 5$ minutes \\
\hline $\begin{array}{l}\text { Vector for } \\
\text { Reporter } \\
\text { plasmid }\end{array}$ & PHH21_F & PHH21_R & $98^{\circ} \mathrm{C} / 30$ seconds & $\begin{array}{l}98^{\circ} \mathrm{C} / 10 \text { seconds } \\
67^{\circ} \mathrm{C} / 30 \text { seconds } \\
72^{0} \mathrm{C} / 90 \text { seconds }\end{array}$ & 35 & $72^{\circ} \mathrm{C} / 5$ minutes \\
\hline PB1-FLAG & PB1_For & $\begin{array}{l}\text { PB1_Rev_F } \\
\text { LAG }\end{array}$ & $98^{\circ} \mathrm{C} / 30$ seconds & $\begin{array}{l}98^{\circ} \mathrm{C} / 10 \text { seconds } \\
60^{\circ} \mathrm{C} / 30 \text { seconds } \\
72^{\circ} \mathrm{C} / 90 \text { seconds }\end{array}$ & 35 & $\begin{array}{l}72^{\circ} \mathrm{C} / 10 \\
\text { minutes }\end{array}$ \\
\hline PB1-STOP & PB1_For & $\begin{array}{l}\text { PB1_Rev_S } \\
\text { top }\end{array}$ & $98^{\circ} \mathrm{C} / 30$ seconds & $\begin{array}{l}98^{\circ} \mathrm{C} / 10 \text { seconds } \\
58^{\circ} \mathrm{C} / 30 \text { seconds } \\
72^{\circ} \mathrm{C} / 90 \text { seconds }\end{array}$ & 35 & $\begin{array}{l}72^{\circ} \mathrm{C} / 10 \\
\text { minutes }\end{array}$ \\
\hline PB2-FLAG & PB2_For & $\begin{array}{l}\text { PB2_Rev_F } \\
\text { LAG }\end{array}$ & $98^{0} \mathrm{C} / 30$ seconds & $\begin{array}{l}98^{\circ} \mathrm{C} / 10 \text { seconds } \\
69^{\circ} \mathrm{C} / 30 \text { seconds } \\
72^{\circ} \mathrm{C} / 90 \text { seconds }\end{array}$ & 35 & $\begin{array}{l}72^{0} \mathrm{C} / 10 \\
\text { minutes }\end{array}$ \\
\hline PB2-STOP & PB2_For & $\begin{array}{l}\text { PB2_Rev_S } \\
\text { top }\end{array}$ & $98^{\circ} \mathrm{C} / 30$ seconds & $\begin{array}{l}98^{\circ} \mathrm{C} / 10 \text { seconds } \\
69^{\circ} \mathrm{C} / 30 \text { seconds } \\
72^{\circ} \mathrm{C} / 90 \text { seconds }\end{array}$ & 35 & $\begin{array}{l}72^{0} \mathrm{C} / 10 \\
\text { minutes }\end{array}$ \\
\hline PA-FLAG & PA_For & $\begin{array}{l}\text { PA_Rev_FL } \\
\text { AG }\end{array}$ & $98^{\circ} \mathrm{C} / 30$ seconds & $\begin{array}{l}98^{\circ} \mathrm{C} / 10 \text { seconds } \\
60^{\circ} \mathrm{C} / 30 \text { seconds } \\
72^{0} \mathrm{C} / 90 \text { seconds }\end{array}$ & 35 & $\begin{array}{l}72^{0} \mathrm{C} / 10 \\
\text { minutes }\end{array}$ \\
\hline PA-STOP & PA_For & $\begin{array}{l}\text { PA_Rev_St } \\
\text { op }\end{array}$ & $98^{\circ} \mathrm{C} / 30$ seconds & $\begin{array}{l}98^{\circ} \mathrm{C} / 10 \text { seconds } \\
58^{\circ} \mathrm{C} / 30 \text { seconds } \\
72^{\circ} \mathrm{C} / 90 \text { seconds }\end{array}$ & 35 & $\begin{array}{l}72^{0} \mathrm{C} / 10 \\
\text { minutes }\end{array}$ \\
\hline NP-FLAG & NP_For & NP_Rev_V5 & $98^{\circ} \mathrm{C} / 30$ seconds & $\begin{array}{l}98^{0} \mathrm{C} / 10 \text { seconds } \\
64^{0} \mathrm{C} / 30 \text { seconds } \\
72^{0} \mathrm{C} / 90 \text { seconds }\end{array}$ & 35 & $\begin{array}{l}72^{0} \mathrm{C} / 10 \\
\text { minutes }\end{array}$ \\
\hline NP-STOP & NP_For & $\begin{array}{l}\text { NP_Rev_St } \\
\text { op }\end{array}$ & $98^{\circ} \mathrm{C} / 30$ seconds & $\begin{array}{l}98^{\circ} \mathrm{C} / 10 \text { seconds } \\
66^{\circ} \mathrm{C} / 30 \text { seconds } \\
72^{\circ} \mathrm{C} / 90 \text { seconds }\end{array}$ & 35 & $\begin{array}{l}72^{0} \mathrm{C} / 10 \\
\text { minutes }\end{array}$ \\
\hline
\end{tabular}

\section{Declaration of competing interest:}

544 The authors declare that they have no known competing financial interests or personal

545 relationships that could have appeared to influence the work reported in this paper.

\section{Acknowledgement:}

547 We sincerely acknowledge Prof. Andrew Mehle (University of Wisconsin Madison) for proving us 548 various valuable plasmids. We acknowledge Indian Institute of Technology Kharagpur for 549 providing us infrastructural support. A.M. acknowledges DBT, Ramalingaswami re-entry 
fellowship (BT/RLF/Re-entry/02/2015), DST-SERB, Early Career Research Award 551 (ECR/2017/001896) and MHRD, "Scheme for Transformational and Advanced Research in 552 Science" \{STARS/APR2019/BS/369/FS (Project ID: 369)\} for financial support. S.B. (File number 553 09/081(1301)/2017-EMR-I) and N.K. (File number 09/081(1316)/2017-EMR-I) acknowledge the 554 Council of Scientific and Industrial Research for their fellowship.

\section{Address of correspondence:}

Dr. Arindam Mondal, Assistant Professor, School of Bioscience, Indian Institute of Technology Kharagpur, Kharagpur-721302, Dist- Paschim Medinipur, West Bengal, India. E-mail address:

558 arindam.mondal@iitkgp.ac.in.

\section{References:}

560 1. Francis T (1940) A new type of virus from epidemic influenza. Science (80- ) 92:405-408 . doi:

$561 \quad 10.1126 /$ SCIENCE.92.2392.405

562 2. Sharma L, Rebaza A, Cruz CS Dela (2019) When "B" becomes "A": the emerging threat of 563 influenza B virus. Eur Respir J 54: . doi: 10.1183/13993003.01325-2019

$564 \quad 3 . \quad$ U.S. Influenza Surveillance: Purpose and Methods | CDC.

$565 \quad$ https://www.cdc.gov/flu/weekly/overview.htm. Accessed 2 Nov 2021

566 4. Flu Symptoms \& Complications | CDC. https://www.cdc.gov/flu/symptoms/symptoms.htm.

$567 \quad$ Accessed 2 Nov 2021

568 5. JA M, T S, AR I (2004) Multiple genotypes of influenza B virus circulated between 1979 and 2003.

6. Xu C, Chan K-H, Tsang TK, et al (2015) Comparative Epidemiology of Influenza B Yamagata- and J Virol 78:12817-12828 . doi: 10.1128/JVI.78.23.12817-12828.2004

578 10. Bouvier NM, Palese P (2008) THE BIOLOGY OF INFLUENZA VIRUSES. Vaccine 26:D49

579 11. H F, AP W, L C, et al (2019) Structures of influenza A virus RNA polymerase offer insight into viral

7. Ambrose CS, Levin MJ (2012) The rationale for quadrivalent influenza vaccines. Hum Vaccin 政: 10.1093/AJE/KWV110

8. Dumm RE, Heaton NS The Development and Use of Reporter Influenza B Viruses. doi: $10.3390 / \mathrm{v} 11080736$

9. Krammer F, Smith GJD, Fouchier RAM, et al (2018) Influenza. Nat. Rev. Dis. Prim. 4:1-21

genome replication. Nature 573:287-290 . doi: 10.1038/S41586-019-1530-7

12. Lutz A, Dyall J, Olivo PD, Pekosz A (2005) Virus-inducible reporter genes as a tool for detecting and quantifying influenza A virus replication. J Virol Methods 126:13-20 . doi: 10.1016/j.jviromet.2005.01.016

13. Zhu W, Zhou J, Qin K, et al (2011) A reporter system for assaying influenza virus RNP functionality based on secreted Gaussia luciferase activity. Virol J 8:29 . doi: 10.1186/1743-422X8-29 
587 14. Dadonaite B, Gilbertson B, Knight ML, et al (2019) The structure of the influenza A virus genome. Nat Microbiol 2019411 4:1781-1789 . doi: 10.1038/s41564-019-0513-7

589 15. Szymkowiak C, Kwan WS, Su Q, et al (2003) Rapid method for the characterization of 3' and 5' $590 \quad$ UTRs of influenza viruses. J Virol Methods 107:15-20 . doi: 10.1016/S0166-0934(02)00184-2

591 16. Flick R, Hobom G (1999) Interaction of influenza virus polymerase with viral RNA in the

17. Ferhadian D, Contrant M, Printz-Schweigert A, et al (2018) Structural and Functional Motifs in Influenza Virus RNAs. Front Microbiol 0:559 . doi: 10.3389/FMICB.2018.00559

18. Park YW, Katze MG (1995) Translational Control by Influenza Virus IDENTIFICATION OF CISACTING SEQUENCES AND TRANS-ACTING FACTORS WHICH MAY REGULATE SELECTIVE VIRAL mRNA TRANSLATION*. doi: 10.1074/jbc.270.47.28433

19. Fodor E, Palese † Peter, Brownlee GG, et al (1998) Attenuation of Influenza A Virus mRNA Levels by Promoter Mutations. J Virol 72:6283 . doi: 10.1128/jvi.72.8.6283-6290.1998

600 20. Neumann G, Zobel A, Hobom G (1994) RNA Polymerase I-Mediated Expression of Influenza Viral

21. Sherry L, Smith M, Davidson S, Jackson D (2014) The N Terminus of the Influenza B Virus

Nucleoprotein Is Essential for Virus Viability, Nuclear Localization, and Optimal Transcription and Replication of the Viral Genome. doi: 10.1128/JVI.01542-14

22. Luytjes W, Krystai M, Enami M, et al (1989) Amplification, Expression, and Packaging of a Foreign

23. Parvin JD, Palese P, Honda A, et al (1989) Promoter analysis of influenza virus RNA polymerase.

24. Li Y, Larrimer A, Curtiss $\mathrm{T}$, et al Influenza virus assays based on virus-inducible reporter cell lines. doi: 10.1111/j.1750-2659.2009.00095.x

25. Wang Z, Duke GM (2007) Virology Journal Cloning of the canine RNA polymerase I promoter and

26. Moncorge O, Long JS, Cauldwell A V., et al (2013) Investigation of Influenza Virus Polymerase

27. Wakai C, Iwama M, Mizumoto K, Nagata K (2011) Recognition of Cap Structure by Influenza B 102

28. Muramoto Y, Takada A, Fujii K, et al (2006) Hierarchy among Viral RNA (vRNA) Segments in Virus RNA Polymerase Is Less Dependent on the Methyl Residue than Recognition by Influenza A Virus Polymerase. J Virol 85:7504 . doi: 10.1128/JVI.02375-10

29. Zhang Z, Zhang H, Xu L, et al (2020) Selective usage of ANP32 proteins by influenza B virus 10.1128/JVI.80.5.2318-2325.2006

30. Eisfeld AJ, Neumann G, Kawaoka Y (2014) Influenza A virus isolation, culture and identification. Nat Protoc 9:2663-2681 . doi: 10.1038/NPROT.2014.180 
31. Ivshina A V., Vodeiko GM, Kuznetsov VA, et al (2004) Mapping of Genomic Segments of Influenza B Virus Strains by an Oligonucleotide Microarray Method. J Clin Microbiol 42:5793 . doi: 10.1128/JCM.42.12.5793-5801.2004

32. Glover DM (1985) DNA cloning: a practical approach. Volume 1

33. Quan J, Tian J (2009) Circular Polymerase Extension Cloning of Complex Gene Libraries and Pathways. PLoS One 4:6441 . doi: 10.1371/journal.pone.0006441

34. Quan J, Tian J (2011) Circular polymerase extension cloning for high-throughput cloning of complex and combinatorial DNA libraries. Nat Protoc 6:242-251 . doi: 10.1038/nprot.2010.181

35. Santos JJS, Finch C, Sutton T, et al (2017) Development of an Alternative Modified Live Influenza B Virus Vaccine. J Virol 91: . doi: 10.1128/JVI.00056-17/FORMAT/EPUB

36. Tisoncik JR, Billharz R, Burmakina S, et al (2011) The NS1 protein of influenza A virus suppresses interferon-regulated activation of antigen-presentation and immune-proteasome pathways. J Gen Virol 92:2093 . doi: 10.1099/VIR.0.032060-0

37. Nogales A, Aydillo T, Ávila-Pérez G, et al (2019) Functional Characterization and Direct Comparison of Influenza A, B, C, and D NS1 Proteins in vitro and in vivo. Front Microbiol 10:2862 . doi: 10.3389/FMICB.2019.02862/BIBTEX

38. Mahmoudian S, Auerochs S, Gröne M, Marschall M (2009) Influenza A virus proteins PB1 and NS1 are subject to functionally important phosphorylation by protein kinase C. J Gen Virol 90:1392-1397 . doi: 10.1099/VIR.0.009050-0

39. Huang X, Zheng M, Wang P, et al (2017) ARTICLE An NS-segment exonic splicing enhancer regulates influenza $A$ virus replication in mammalian cells. doi: 10.1038/ncomms 14751

40. Salvatore M, Basler CF, Parisien J-P, et al (2002) Effects of Influenza A Virus NS1 Protein on Protein Expression: the NS1 Protein Enhances Translation and Is Not Required for Shutoff of Host Protein Synthesis. J Virol 76:1206-1212 . doi: 10.1128/JVI.76.3.1206-1212.2002

41. Chen G, Liu CH, Zhou L, Krug RM (2014) Cellular DDX21 RNA helicase inhibits influenza A virus replication but is counteracted by the viral NS1 protein. Cell Host Microbe 15:484-493 . doi: 10.1016/j.chom.2014.03.002

42. Mok BW-Y, Song W, Wang P, et al (2012) The NS1 Protein of Influenza A Virus Interacts with Cellular Processing Bodies and Stress Granules through RNA-Associated Protein 55 (RAP55) during Virus Infection. J Virol 86:12695 . doi: 10.1128/JVI.00647-12

43. Dauber B, Heins G, Wolff T (2004) The Influenza B Virus Nonstructural NS1 Protein Is Essential for Efficient Viral Growth and Antagonizes Beta Interferon Induction. J Virol 78:1865 . doi: 10.1128/JVI.78.4.1865-1872.2004

44. Yuan W, Krug RM (2001) Influenza B virus NS1 protein inhibits conjugation of the interferon (IFN)induced ubiquitin-like ISG15 protein. EMBO J 20:362 . doi: 10.1093/EMBOJ/20.3.362

45. Mondal A, Dawson AR, Potts GK, et al (2017) Influenza virus recruits host protein kinase C to control assembly and activity of its replicat ion machinery. Elife 6: . doi: 10.7554/eLife.26910

46. Graci JD, Cameron CE (2006) Mechanisms of action of ribavirin against distinct viruses. Rev Med Virol 16:37-48 . doi: 10.1002/RMV.483 
47. Furuta $\mathrm{Y}$, Komeno T, Nakamura $\mathrm{T}$ (2017) Favipiravir (T-705), a broad spectrum inhibitor of viral RNA polymerase. Proc Jpn Acad Ser B Phys Biol Sci 93:449-463 . doi: 10.2183/PJAB.93.027

48. Gish RG (2006) Treating HCV with ribavirin analogues and ribavirin-like molecules. J Antimicrob Chemother 57:8-13 . doi: 10.1093/JAC/DKI405

49. Oxford JS (1975) Inhibition of the replication of influenza A and B viruses by a nucleoside analogue (ribavirin). J Gen Virol 28:409-414 . doi: 10.1099/0022-1317-28-3-409

671 50. Cheung PPH, Watson SJ, Choy KT, et al (2014) Generation and characterization of influenza A viruses with altered polymerase fidelity. Nat Commun 2014 51 5:1-13 . doi: 10.1038/ncomms5794

51. McCracken EA, McCracken EA (1976) Double-Blind Clinical Assessment of Ribavirin (Virazole) in the Prevention of Induced Infection with Type B Influenza Virus. J Infect Dis 133:A109-A113 . doi: 10.1093/INFDIS/133.SUPPLEMENT_2.A109

52. Ren L, Peng Z, Chen X, Ouyang H (2016) Live Cell Reporter Systems for Positive-Sense Single Strand RNA Viruses. Appl Biochem Biotechnol 178:1567 . doi: 10.1007/S12010-015-1968-5

53. Su J, Dou Y, You Y, Cai X (2015) Application of minigenome technology in virology research of the Paramyxoviridae family. J Microbiol Immunol Infect 48:123-129 . doi: 